\section{Biodiversity needs a scientific approach}

We agree with Esther Turnhout and colleagues (Nature 488, $454-455$; 2012) that the Intergovernmental Platform on Biodiversity and Ecosystem Services (IPBES) should take citizen knowledge and nonmonetary values into account to improve the science-policy interface for biodiversity protection. Even so, knowledge used to inform policy must be produced through an objective process if it is to withstand scrutiny. This demands a science-based approach.

Science sets a standard for data quality, not for who collects the data. It provides a common currency for understanding the consequences for biodiversity of actions arising from the values of different stakeholders, including local communities, huntergatherers, commercial exploiters and conservationists.

The role of IPBES in policy formulation means that it will inevitably meet resistance that will seek to undermine data credibility, the assessment process and the platform itself. Instead of avoidance strategies, we need mechanisms for successful negotiation of such controversies to support transformation. David A. Westcott, Frederieke J. Kroon, Andy W. Sheppard CSIRO Ecosystem Sciences, Australia.

david.westcott@csiro.au

\section{Change of heart on nanoparticle risks}

You contend that most nanotechnology researchers now acknowledge that some areas of their work raise legitimate environmental, health and safety concerns (Nature 488, 576-579; 2012). This was not the case a decade ago, when we at the Action Group on Erosion, Technology and Concentration (ETC) called for a moratorium on the commercialization of products containing engineered nanoparticles.

In 2002, scientists could point us to only one peer-reviewed study of nanotube toxicity, and companies were still sending a Material Safety Data Sheet for graphite with carbon nanotube shipments. ETC's concerns were dismissed as alarmist. We welcome the change in attitude.

ETC's central concern has always been the economic impact on populations in developing countries resulting from the market disruptions that are expected with the advent of new nanoproducts and processes. We have consistently dismissed the hypothetical concept of 'grey goo' — uncontrolled self-replicating nanorobots - as a red herring.

Finally, ETC has no connection to ITS, the group that claimed responsibility for the nanotech-related bombings in Mexico. ETC opposes violence in all forms.

Silvia Ribeiro ETC Group,

Mexico City, Mexico.

etc@etcgroup.org

\section{Fleischmann denied due credit}

Philip Ball's obituary of Martin

Fleischmann (Nature 489, 34;

2012), like many others, ignores the experimental evidence contradicting the view that cold fusion is 'pathological science' (see www.lenr.org). I gave an alternative perspective in my obituary of Fleischmann in The Guardian (see go.nature. com/rzukfz), describing what I believe to be the true nature of what Ball calls a "Shakespearean tragedy".

The situation at the time of the announcement of cold fusion was confused because of errors in the nuclear measurements (neither Fleischmann nor his co-worker Stanley Pons had expertise in this area) and because of the difficulty researchers had with replication. Such problems are not unusual in materials science. Some were able, I contend, to get the experiment to work (for example, M. C. H. McKubre et al. J. Electroanal. Chem. 368, 55-56; 1994; E. Storms and C. L. Talcott Fusion Technol. 17, 680; 1990) and, in my view, to confirm both excess heat and nuclear products.

Scepticism also arose because the amount of nuclear radiation observed was very low compared with that expected from the claimed levels of excess heat. But it could be argued that the experiment never excluded the possibility that the liberated energy might be taken up directly by the metal lattice within which the hydrogen molecules were absorbed.

In my opinion, none of this would have mattered had journal editors not responded to this scepticism, or to emotive condemnation of the experimenters, by setting an unusually high bar for publication of papers on cold fusion. This meant that most scientists were denied a view of the accumulating positive evidence.

The result? Fleischmann was effectively denied the credit due to him, and doomed to become the tragic figure in Ball's account. Brian D. Josephson University of Cambridge, UK. bdj10@cam.ac.uk

\section{European biodiesel can be sustainable}

An accurate evaluation of the sustainability of European oilseed rape for biodiesel production would be a useful resource in discussions of the European Union's bioenergy policies. Your ill-judged pronouncement in an online News report that rapeseed biodiesel fails the sustainability test (Nature http://doi.org/ jdn; 2012) risks confusing the facts by quoting questionable figures from a preliminary study (G. Pehnelt and C. Vietze Jena Econ. Res. Pap. 039; 2012).

These figures concern some of the most important parameters used in sustainability calculations. The study considerably underestimated mean annual seed yields of rapeseed used for biodiesel, by using outdated yield values from the entire European Union (around 2.8 tonnes per hectare for 1991-2005), rather than current yields from the principal biodiesel-producing countries such as Germany (3.8 tonnes per hectare for 2005-10; see http://faostat3.fao.org). The input values were also based on energy-intensive production procedures (deodorization, for example) that are only used in processing rapeseed oil for food, and on unrealistic transportation emission values. Incorrect input data can seriously influence the outcome of a sustainability evaluation.

Political decisions need to be based on reasoned and constructive discussion about issues as controversial as renewable biofuels, which in turn must be based on strong, peer-reviewed science. Rod Snowdon, Wolfgang Friedt Justus Liebig University, Giessen, Germany. rod.snowdon@agrar.uni-giessen.de

\section{Reviews turn facts into understanding}

Your Editorial on $h$-index forecasting (Nature 489, 177; 2012) perpetuates the myth that: "Review articles, which may not add much to the research, count the same as original research papers, which contribute a great deal." Probably the reverse is true. A research paper usually provides just one or two new facts, whereas reviews synthesize our understanding more broadly and make it more concrete.

Some reviews summarize thousands of papers (see, for instance, D. B. Kell BMC Med. Genom. 2, 2; 2009) and turn an inchoate and stochastic scientific literature into knowledge.

Douglas B. Kell University of Manchester, UK. dbk@manchester.ac.uk 